\title{
The effect of maternal high-fat-diet mediated oxidative stress on ovarian function in mice offspring
}

\author{
SHI YAN ${ }^{1 *}$, FENGJUAN WANG ${ }^{2 *}$ and QINGYUN SHI ${ }^{2}$ \\ ${ }^{1}$ Department of Obstetrics and Gynecology, Peking University Third Hospital, Beijing 100191; \\ ${ }^{2}$ Department of Obstetrics and Gynecology, Beijing Obstetrics and Gynecology Hospital, \\ Capital Medical University, Beijing 100026, P.R. China
}

Received February 8, 2020; Accepted July 23, 2020

DOI: $10.3892 / \mathrm{etm} .2020 .9264$

\begin{abstract}
A maternal high-fat diet (HFD) has been shown to exert deleterious effects on fetal programming by impairing embryo growth, and exerts a long-term effect on the health of offspring. The present study aimed to evaluate the effect of a maternal HFD on the ovaries of offspring from the perspective of oxidative stress. Female C57BL/6J mice were randomly assigned to four groups fed various HFDs during the preconception (4 weeks) and gestation-lactation periods. Offspring were fed a normal diet after weaning, and serum and ovaries were collected at 10 weeks of age. The developmental status of follicles was observed using hematoxylin and eosin staining. The serum oxidative stress levels and insulin resistance were detected using ELISA test kits. The expression of phosphorylated form of $\mathrm{H} 2 \mathrm{AX}$ histone variant $(\gamma \mathrm{H} 2 \mathrm{AX})$, forkhead box protein $\mathrm{O} 3 \mathrm{a}$ (FOXO3a), Bcl-2-like protein 11 (Bim)and insulin-like growth factor (IGF)-1 in ovarian tissue was analyzed using reverse transcription-quantitative PCR and western blot analyses to further explore the pathogenic mechanism. Prenatal exposure to a maternal HFD resulted in a reduced number of primordial and preantral follicles in the ovaries of offspring. Exposure to an HFD in the preconception period exerted a greater effect on the offspring compared with exposure to an HFD in the gestation-lactation period. A reduction in fat intake during the preconception, gestation and lactation periods significantly reduced the associated adverse outcomes. The expression of genes (FOXO3a, IGF-1, $\gamma H 2 A X$ and Bim) involved in oxidative stress showed a decreasing trend (high-fat/high-fat>high-fat/control>control/high-fat $>$ control/control) in the ovaries of offspring. Overall, HFD
\end{abstract}

Correspondence to: Dr Qingyun Shi, Department of Obstetrics and Gynecology, Beijing Obstetrics and Gynecology Hospital, Capital Medical University, 251 Yao Jia Yuan Road, Chaoyang, Beijing 100026, P.R. China

E-mail: shiqingyun1@163.com

*Contributed equally

Key words: ovarian function, high-fat diet, oxidative stress, endocrine, nutrition exposure during the preconception period exerted a greater effect on offspring compared with HFD exposure during the gestation-lactation period. The long-term effect on follicular growth and development may be associated with increased oxidative stress and the activation of the insulin/PI3K/Akt pathway.

\section{Introduction}

Obesity, which is associated with hormonal and metabolic imbalances, is a common problem among pregnant women. It frequently leads to adverse pregnancy outcomes, such as premature delivery, dystocia, fetal macrosomia (1). Based on accumulating evidence by both clinical and animal studies, an intrauterine high-fat environment plays a crucial role in the development of diseases in offspring, such as hypertension, diabetes and nervous system diseases such as schizophrenia $(1,2)$. Generally, the response of embryos to an adverse intrauterine environment consists of adaptive changes. These adjustments to stress or stimulation continuously alter the physiological and metabolic functions of the body. Even after the stimulus has been removed, the effect remains and becomes a key factor contributing to chronic diseases in adults $(2,3)$. Animal experiments have shown that obesity leads to lower fertility through alterations in various metabolic pathways, including insulin metabolism, sex hormones signaling and follicular development (4). After performing hematoxylin-eosin $(\mathrm{H} \& \mathrm{E})$ staining of ovarian tissue from pregnant mice fed a high-fat diet (HFD), researchers observed significantly decreased numbers of follicles at all levels in the offspring of mothers fed a HFD compared with the offspring of mothers fed a control diet (5). However, the mechanisms by which a maternal HFD leads to reproductive abnormalities in offspring remain unclear.

Reactive oxygen species (ROS) play important roles in mediating hormonal signaling, oocyte formation, steroidogenesis, follicle formation, ovulation, corpus luteum formation and germ cell function, thus regulating the female reproductive system. However, when ROS are overproduced, oxidative stress (OS) is initiated, causing cytotoxic effects and irreversible damage to the organism (6). Superoxide dismutase (SOD) is the primary antioxidant enzyme in the body, and malondialdehyde (MDA) is produced by lipid 
peroxidation. Both of these molecules serve as indicators of OS in vivo $(7,8)$. The present study established an HFD model in female mice by establishing four groups fed various HFDs during the preconception period (4 weeks) and the gestation-lactation period, and OS levels (SOD and MDA) and insulin resistance in the offspring were analyzed to investigate the effects and mechanisms of maternal HFD on the reproductive function of offspring. Additionally, the developmental status of follicles was observed using H\&E staining. Reverse transcription-quantitative (RT-q)PCR and western blot analyses were performed to analyze the expression of DNA damage markers, such as phosphorylated form of H2AX histone variant $(\gamma \mathrm{H} 2 \mathrm{AX})$, forkhead box protein $\mathrm{O} 3 \mathrm{a}$ (FOXO3a), Bcl-2-like protein 11 (Bim) and insulin-like growth factor (IGF)-1, in ovarian tissue and to further explore the pathogenic mechanism. In addition, a dietary intervention was added to experimental subgroups. The present study aimed to determine the effect of an HFD on otherwise healthy mice during pregnancy on the reproductive function of offspring and to determine whether reproductive function was improved by adjusting the diet program in the HFD group. These results may provide guidance for pregnancy preparation and for clinical interventions during pregnancy.

\section{Materials and methods}

Animal treatment. All animals were provided by the Laboratory Animal Center of Capital Medical University, and the study protocol was approved by the Local Ethics Review Committee of Capital Medical University Beijing Obstetrics and Gynecology Hospital (approval no. AEEI-2019-111). Female C57BL/6J mice ( $\mathrm{n}=24$; 8 weeks old; weight, 18-20 g) were randomly divided into four groups, housed under a 12-h light/dark cycle (lights on at 07:00 h) at a constant temperature of $22 \pm 2^{\circ} \mathrm{C}$, with food and water available ad libitum. A total of 12 male mice were mated with female mice in estrus state at a ratio of 1:2. The HF/HF group was fed an HFD $(60 \% \mathrm{kcal}$ fat; Research Diets, Inc.) during the preconception period (4 weeks) and the gestation-lactation period. The HF/C group was fed a HFD at preconception (4 weeks) and a normal diet during the gestation-lactation period. The $\mathrm{C} / \mathrm{HF}$ group was fed a normal diet in the preconception period (4 weeks) and a HFD in the gestation-lactation period. Finally, the $\mathrm{C} / \mathrm{C}$ group was fed a regular diet in both the preconception and gestation-lactation periods. A total of 90 female offspring were group housed after weaning at 28 days of age. We collected 16 of the offspring from each group that were fed a normal diet until 10 weeks of age. The offspring were sacrificed at diestrus, as identified by a vaginal smear. Mice were fasted for $12 \mathrm{~h}$ before been sacrificed. For ethical reasons, mice were exposed to $3 \%$ isoflurane for $15 \mathrm{~min}$ before sampling. Skin pinch reaction and stimulate toe response were used to confirm the depth of anesthesia. The mice were euthanized by decapitation. Fresh blood samples $(1 \mathrm{ml})$ were obtained from the mother and offspring, and the serum was collected and stored at $-80^{\circ} \mathrm{C}$. Sixty-four pairs of ovaries were collected. The left ovary was fixed with $10 \%$ neutral buffered formaldehyde for $24 \mathrm{~h}$ at $25^{\circ} \mathrm{C}$ and processed for histological analysis, while the right ovary was immediately frozen in liquid nitrogen and stored at $-80^{\circ} \mathrm{C}$ until the gene expression analysis.
Analysis of the OS levels. The SOD and MDA levels in serum samples from the mother and offspring were analyzed to evaluate OS. All steps were performed strictly in accordance with the test kit instructions [Malondialdehyde (MDA) assay kit (cat. no. A003-1-2) and Superoxide Dismutase (SOD) assay kit (cat. no. A001-3-2)] provided by the Nanjing Jiangcheng Bioengineering Institute Co., Ltd. The blood glucose and total cholesterol levels were also measured using an automatic biochemical analyzer. Serum insulin, testosterone and follicle-stimulating hormone (FSH) levels were measured using an ELISA kit (Nanjing Jiangcheng Bioengineering Institute Co., Ltd.) according to the manufacturer's instructions (follice stimulating hormone assay kit, cat. no. cH101; insulin assay kit, cat. no. H203; testosterone assay kit, cat. no. H090). Furthermore, the insulin resistance index was calculated based on fasting glucose and insulin levels [plasma glucose levels (GLU, mmol/l) x serum insulin levels (mIU/l)/22.5].

Histological analysis of the ovaries. One ovary from each offspring was fixed with $10 \%$ neutral buffered formaldehyde $\left(24 \mathrm{~h}, 25^{\circ} \mathrm{C}\right)$, embedded in paraffin, and serially sectioned to a thickness of $4-\mu \mathrm{m}$ at $50-\mathrm{mm}$ intervals at fixed points in all ovaries. Sections were stained with $\mathrm{H} \& \mathrm{E}$ at $25^{\circ} \mathrm{C}$ for the morphometric analysis. Additionally, some sections were stained with an anti-Mullerian hormone antibody (Abcam) overnight at $4^{\circ} \mathrm{C}$ to assist with the identification of granulosa tissue in the follicles. Only follicles with a visible oocyte nuclei were included, and follicles showing evidence of atresia were excluded. All morphometric analyses were performed by the same observer, and an independent researcher was blinded to the experimental group from which the sections were obtained during the analysis. The total area of each section was calculated (area $\mathrm{x}$ thickness of section), and the number of follicles for each animal were counted and the total area of the ovarian tissue was calculated. The number of primordial follicles was reported as the number of follicles per $\mathrm{mm}^{2}$, while the numbers of antral and graafian follicles are reported on a per ovary basis.

Gene expression analysis. The expression of $I G F-1, F O X O 3 a$, $\gamma H 2 A X$ and Bim mRNA was measured using RT-qPCR. Total RNA was extracted from the ovary tissues using TRIzol ${ }^{\circledR}$ reagent (Sigma-Aldrich; Merck KGaA). Reverse transcription was performed using a SuperScript First-Strand Synthesis system (Invitrogen; Thermo Fisher Scientific; $42^{\circ} \mathrm{C}$ for $50 \mathrm{~min}$, $95^{\circ} \mathrm{C}$ for $5 \mathrm{~min}$ ). qPCR was carried out on a $7900 \mathrm{HT}$ real-time PCR system with SYBR Premix Ex Taq II (Takara Bio, Inc.). the thermocycling conditions were as follows: $50^{\circ} \mathrm{C}$ for $2 \mathrm{~min}$, $95^{\circ} \mathrm{C}$ for $10 \mathrm{~min},\left(95^{\circ} \mathrm{C}\right.$ for $15 \mathrm{sec}, 60^{\circ} \mathrm{C}$ for $\left.1 \mathrm{~min}\right) \mathrm{x} 40$ cycles (generate amplification curve), $95^{\circ} \mathrm{C}$ for $15 \mathrm{sec}, 60^{\circ} \mathrm{C}$ for $15 \mathrm{sec}, 95^{\circ} \mathrm{C}$ for $15 \mathrm{sec}$ (generate dissolution curve). The $2^{-\Delta \Delta \mathrm{Cq}}$ method was used for expression analysis (9). Gene-specific primers and probes were designed using Prime Express software (version 3.0.1, Thermo Fisher Scientific, Inc; cat. no. 4363991) and purchased from Shanghai GenePharma Co., Ltd. The sequences of the primers used in the present study are as shown in Table SI. All reactions were performed at least three times, and the products were analyzed using a Roche Light Cycler 480. $\beta$-actin was included in all reactions as an internal housekeeping control. 
Table I. Serum Glu, TC, insulin, T and FSH levels in female offspring mice (mean \pm SD, $n=16$ ).

\begin{tabular}{lrrrr}
\hline & \multicolumn{3}{c}{ Diet group } \\
\cline { 2 - 5 } Marker & \multicolumn{1}{c}{ HF/HF } & HF/C & \multicolumn{1}{c}{$\mathrm{C} / \mathrm{HF}$} & \\
\hline Glu, mmol/l & $11.72 \pm 1.44^{\mathrm{a}-\mathrm{c}}$ & $8.22 \pm 1.01^{\mathrm{a}}$ & $7.45 \pm 0.95^{\mathrm{a}}$ & $5.82 \pm 0.88$ \\
TC, mmol/l & $4.94 \pm 0.83^{\mathrm{a}-\mathrm{c}}$ & $3.63 \pm 0.66^{\mathrm{a}}$ & $3.24 \pm 0.20^{\mathrm{a}}$ & $2.70 \pm 0.33$ \\
Insulin, mU/l & $29.39 \pm 2.79^{\mathrm{a}-\mathrm{c}}$ & $25.97 \pm 2.05^{\mathrm{a}}$ & $20.11 \pm 3.36^{\mathrm{a}, \mathrm{b}}$ & $11.33 \pm 1.72$ \\
HOMA-IR & $15.48 \pm 3.28^{\mathrm{a}-\mathrm{c}}$ & $9.57 \pm 1.86^{\mathrm{a}}$ & $6.80 \pm 2.08^{\mathrm{a}, \mathrm{b}}$ & $2.99 \pm 0.89$ \\
T, nmol/l & $21.54 \pm 0.65^{\mathrm{a}-\mathrm{c}}$ & $16.92 \pm 0.66^{\mathrm{a}}$ & $7.48 \pm 0.54^{\mathrm{a}, \mathrm{b}}$ & $5.48 \pm 0.41$ \\
FSH, mIU/ml & $5.53 \pm 0.37^{\mathrm{a}-\mathrm{c}}$ & $7.02 \pm 0.45^{\mathrm{a}}$ & $10.47 \pm 0.47^{\mathrm{a}, \mathrm{b}}$ & $12.53 \pm 0.47$ \\
\hline
\end{tabular}

Glu, glucose; TC, total cholesterol; HOMA-IR, the insulin resistance index; T, testosterone; FSH, follicle-stimulating hormone; HF, high fat; $\mathrm{C}$, control; $\mathrm{X}$, mean; ${ }^{\mathrm{P}}<0.05$ vs. the $\mathrm{C} / \mathrm{C}$ group; ${ }^{\mathrm{P}}<0.05$ vs. the $\mathrm{HF} / \mathrm{C}$ group; ${ }^{\mathrm{C}} \mathrm{P}<0.05$ vs. the $\mathrm{C} / \mathrm{HF}$ group.

Western blot analysis. Total cellular protein was extracted using lysis buffer (50 mmol HEPES, $1 \mathrm{mmol} \mathrm{MgCl}_{2}, 10 \mathrm{mmol}$ ethylenediaminetetraacetic acid, $1 \%$ Triton $\mathrm{X}-100, \mathrm{pH}$ 6.4). The protein levels were quantified using a BCA Protein Assay kit (Beyotime Institute of Biotechnology). The protein expression levels of IGF-1, FOXO3a, $\gamma \mathrm{H} 2 \mathrm{AX}$, Bim and $\beta$-actin in ovaries were analyzed using western blotting. In total, $30 \mu \mathrm{g}$ protein was loaded per lane onto a $12 \%$ gel and resolved using SDS-PAGE. After electrophoresis, proteins were transferred to a nitrocellulose membrane. After being blocked with $5 \%$ lipid-free milk solution for $2 \mathrm{~h}$ at room temperature (RT). The membrane was probed with primary antibodies against IGF-1, FOXO3a, $\gamma \mathrm{H} 2 \mathrm{AX}$, Bim and $\beta$-actin [1:1,000; Abcam, Anti-Bim antibody, cat. no. ab32158; Anti-IGF1 antibody, cat. no. ab9572; Anti-gamma H2A.X (phospho S139) antibody (9F3), cat. no. ab26350; Anti-FOXO3a antibody, cat. no. ab23683] at RT for $2 \mathrm{~h}$. The secondary horseradish peroxidase-conjugated antibody was anti-rabbit (1:10,000, Santa Cruz Biotechnology, Inc.) at RT for $2 \mathrm{~h}$. Protein bands were visualized using the diaminobenzidine detection kit (cat. no. SW2010; Beijing Solarbio Science \& Technology Co., Ltd.). The densities of sample bands were analyzed with Quantity One analysis software 1709600 (Bio-Rad Laboratories, Inc.).

Statistical analysis. The experimental data were analyzed using SPSS version 21 (IBM Corp) for MacBook. All data are presented as mean \pm standard deviation from at least three independent repetitions. One-way ANOVA was performed for between-group comparisons. If data showed homogeneity of variance, Tukey's post hoc test was used, otherwise Dunnett's T3 test was used. $\mathrm{P}<0.05$ was considered to indicate a statistically significant difference.

\section{Results}

Serum glucose, total cholesterol, insulin, testosterone and FSH levels in female mouse offspring. Higher glucose and total cholesterol levels were observed in the $\mathrm{HF} / \mathrm{HF}$ and $\mathrm{C} / \mathrm{HF}$ groups compared with those in the $\mathrm{C} / \mathrm{C}$ group $(\mathrm{P}<0.05)$, and the levels measured in the $\mathrm{HF} / \mathrm{HF}$ group were higher compared with those in the C/HF group. Significantly higher insulin levels were measured in the $\mathrm{HF} / \mathrm{HF}$ group compared with those in the $\mathrm{HF} / \mathrm{C}, \mathrm{C} / \mathrm{HF}$ and $\mathrm{C} / \mathrm{C}$ groups (all $\mathrm{P}<0.05$ ), which showed a decreasing trend (Table I, HOMA-IR). Furthermore, the insulin resistance index was calculated based on fasting glucose and insulin levels [plasma glucose levels (GLU, mmol/l) x serum insulin levels $(\mathrm{mIU} / \mathrm{l}) / 22.5]$. The index value also showed a decreasing trend: $\mathrm{HF} / \mathrm{HF}>\mathrm{HF} / \mathrm{C}>\mathrm{C} / \mathrm{HF}$ $>\mathrm{C} / \mathrm{C}$. It demonstrated that a high-fat diet during pregnancy increased insulin levels and the tendency towards insulin resistance in offspring mice. Reducing the intake of fat during the pregnancy and lactation periods effectively improved the level of insulin and insulin resistance. The FSH levels showed the following increasing trend: $\mathrm{HF} / \mathrm{HF}<\mathrm{HF} / \mathrm{C}<\mathrm{C} / \mathrm{HF}<\mathrm{C} / \mathrm{C}$. The testosterone levels in these groups also showed a decreasing trend: Showed a decreasing trend: $\mathrm{HF} / \mathrm{HF}>\mathrm{HF} / \mathrm{C}>\mathrm{C} / \mathrm{HF}>\mathrm{C} / \mathrm{C}$ (all, Table I).

Serum levels of SOD and MDA. Among the groups, significantly lower SOD levels were measured in both the mothers and offspring from the $\mathrm{HF} / \mathrm{HF}$ group compared with those in the $\mathrm{HF} / \mathrm{C}, \mathrm{C} / \mathrm{HF}$ and $\mathrm{C} / \mathrm{C}$ groups (vs. $\mathrm{HF} / \mathrm{HF}$ group, all $\mathrm{P}<0.05)$, which indicated an increasing trend. The highest MDA levels were detected in both the mothers and offspring from the $\mathrm{HF} / \mathrm{HF}$ group, and the following decreasing trend was observed: $\mathrm{HF} / \mathrm{C}>\mathrm{C} / \mathrm{HF}>\mathrm{C} / \mathrm{C}$ (vs. $\mathrm{HF} / \mathrm{HF}$ group, all $\mathrm{P}<0.05$ ). This effect persisted even when the offspring were fed a normal diet. OS was significantly improved by reducing fat intake, as shown in SOD levels and in MDA levels compared with the HF/HF group (Fig. 1A and B, respectively).

Ovarian histology and analysis. The morphometric analyses of ovarian tissue are shown in Fig. 2. The number of primordial follicles, follicular development and number of follicles were increased in the ovaries of offspring from the $\mathrm{C} / \mathrm{C}$ group compared with offspring from the $\mathrm{HF} / \mathrm{HF}$ group. Significantly fewer primordial follicles and preantral follicles were observed in the $\mathrm{HF} / \mathrm{HF}$ group compared with the $\mathrm{C} / \mathrm{C}$ group $(\mathrm{P}<0.05)$. The number of primordial follicles and preantral follicles in the $\mathrm{HF} / \mathrm{C}$ group was lower compared with the $\mathrm{C} / \mathrm{HF}$ group $(\mathrm{P}<0.05)$. The $\mathrm{HF} / \mathrm{HF}$ and $\mathrm{HF} / \mathrm{C}$ groups showed no significant difference in primordial follicles and preantral follicles number $(\mathrm{P}>0.05)$. Moreover, significant differences in the number of antral and graafian follicles were not observed among the groups $(\mathrm{P}>0.05)$. The result showed that HFD reduced the number of primordial and preantral follicles but 

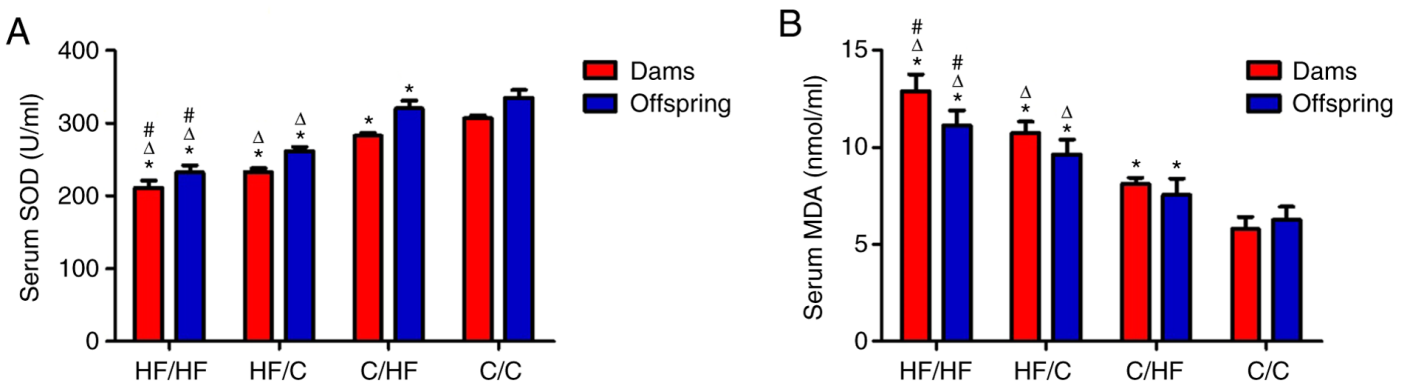

Figure 1. SOD and MDA levels in the dams and offspring. (A) SOD levels in the dams and offspring showed an increasing trend among the HF/C, $\mathrm{C} / \mathrm{HF}$ and $\mathrm{C} / \mathrm{C}$ groups $(\mathrm{P}<0.05)$. (B) MDA levels in the dams and offspring showed a decreasing trend in the $\mathrm{HF} / \mathrm{C}, \mathrm{C} / \mathrm{HF}$ and $\mathrm{C} / \mathrm{C}$ groups $(\mathrm{P}<0.05)$. All values are reported as means $\pm \mathrm{SEM} ;{ }^{*} \mathrm{P}<0.05$ vs. the $\mathrm{C} / \mathrm{C}$ group; ${ }^{*} \mathrm{P}<0.05$ vs. the $\mathrm{HF} / \mathrm{C}$ group; ${ }^{\mathrm{A}} \mathrm{P}<0.05$ vs. the $\mathrm{C} / \mathrm{HF}$ group (one-way ANOVA). SOD, superoxide dismutase; MAD, malondialdehyde; HF, high fat; $\mathrm{C}$, control.

A

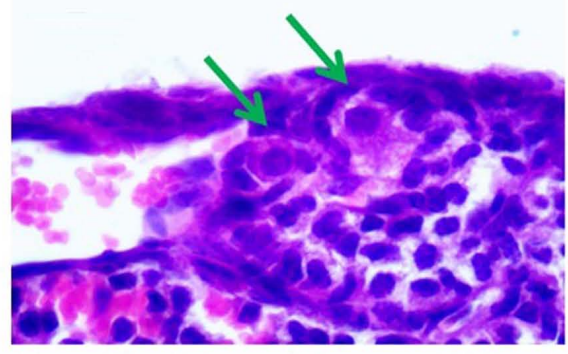

C

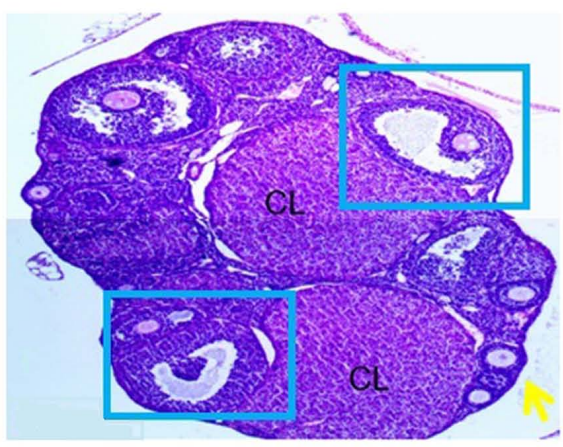

a

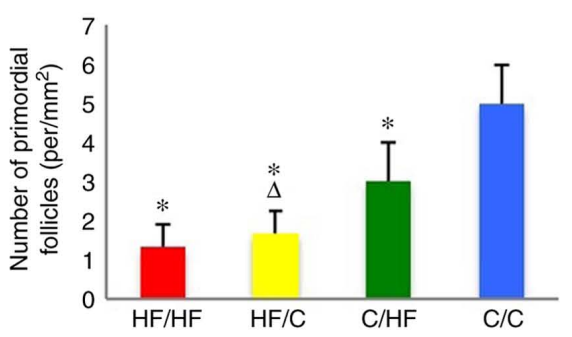

C

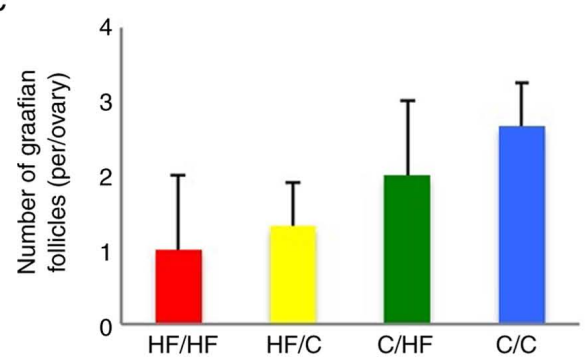

B

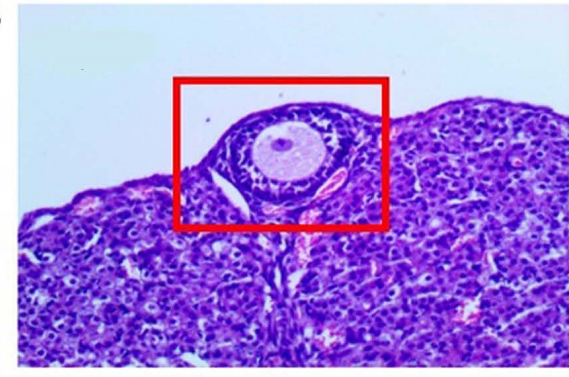

$\mathrm{D}$
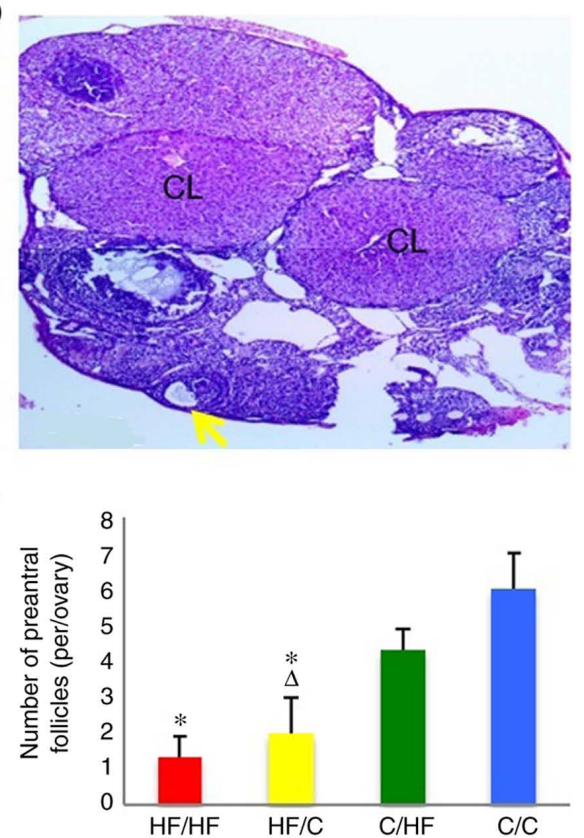

d

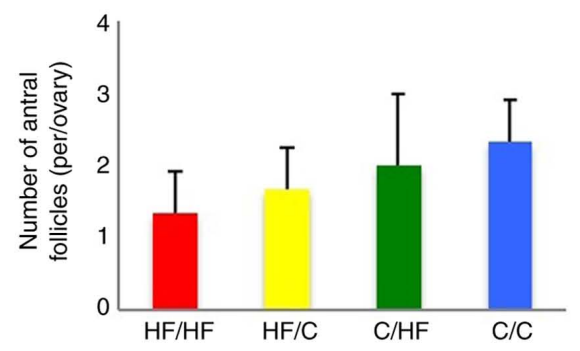

Figure 2. The random photomicrographs of cross-sections of ovaries from (A-C) C/C and (D) HF/HF) female mice stained with hematoxylin and eosin. The green arrows indicate the primordial follicles (scale bar, $50 \mu \mathrm{m}$ ). The red square indicates the preantral follicles (scale bar, $100 \mu \mathrm{m}$ ). The blue squares indicate the graafian follicles (scale bar, $200 \mu \mathrm{m}$ ). The yellow arrows indicate the antral follicles (scale bar, $200 \mu \mathrm{m}$ ). The numbers of (a) primordial follicles, (b) preantral follicles, (c) graafian follicles and (d) antral follicles in 10-week old offspring. The offspring were from the $\mathrm{HF} / \mathrm{HF}, \mathrm{HF} / \mathrm{C}, \mathrm{C} / \mathrm{HF}$ and $\mathrm{C} / \mathrm{C}$ groups (n=16). All values are reported as means $\pm \mathrm{SEM}$. ${ }^{*} \mathrm{P}<0.05$ vs. the $\mathrm{C} / \mathrm{C}$ group; ${ }^{\Delta} \mathrm{P}<0.05$ vs. the $\mathrm{C} / \mathrm{HF}$ group (one-way ANOVA). CL, corpus lutem; $\mathrm{HF}$, high fat; $\mathrm{C}$, control. 
A

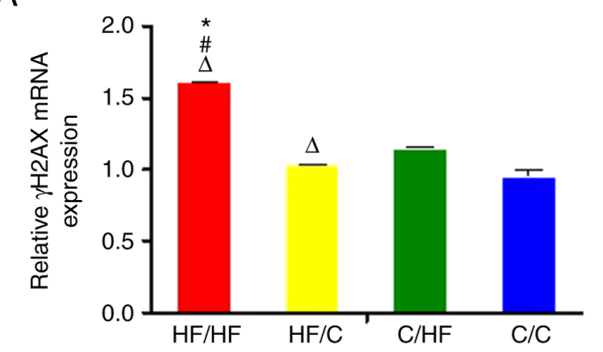

C

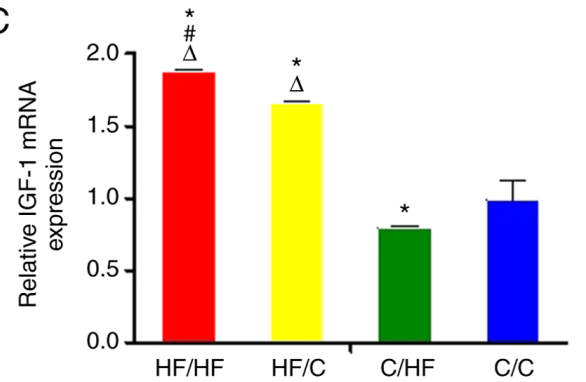

B

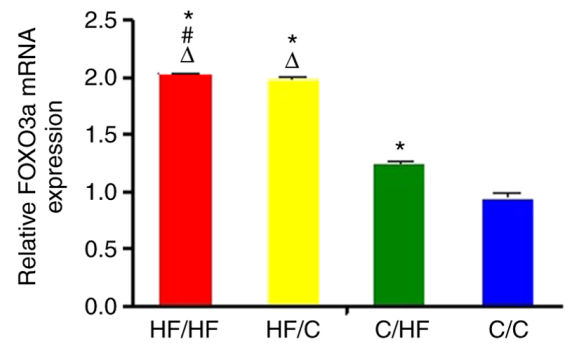

D

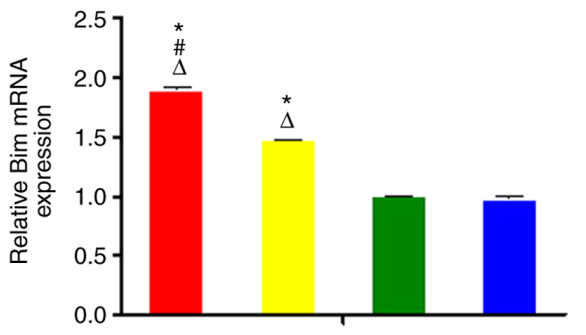

Figure 3. The expression of the (A) $\gamma H 2 A X$, (B) FOXO3a, (C) IGF-1 and (D) Bim mRNAs in ovaries from 10 -week old offspring. The offspring were from the $\mathrm{HF} / \mathrm{HF}, \mathrm{HF} / \mathrm{C}, \mathrm{C} / \mathrm{HF}$ and $\mathrm{C} / \mathrm{C}$ groups $(\mathrm{n}=16)$. The values are presented as the relative fold changes normalized to the $\mathrm{C} / \mathrm{C}$ group, with 1 representing the value obtained for the $\mathrm{C} / \mathrm{C}$ group. All values are reported as means $\pm \mathrm{SEM}$. ${ }^{*} \mathrm{P}<0.05$ vs. the $\mathrm{C} / \mathrm{C}$ group; ${ }^{*} \mathrm{P}<0.05$ vs. the $\mathrm{HF} / \mathrm{C}$ group; ${ }^{\Delta} \mathrm{P}<0.05$ vs. the $\mathrm{C} / \mathrm{HF}$ group (one-way ANOVA). FOXO3a, forkhead box protein O3a; IGF-1, insulin-like growth factor 1; $\gamma \mathrm{H} 2 \mathrm{AX}$, phosphorylated form of $\mathrm{H} 2 \mathrm{AX}$ histone variant; Bim, Bcl-2-like protein 11; HF, high fat; C, control.

had little effect on antral and graafian follicles. In addition, exposure to the HFD in the preconception period exerted a greater effect on the number of primordial and preantral follicles in offspring compared with a HFD in the pregnancy and lactation periods, as presented in $\mathrm{HF} / \mathrm{C}$ and $\mathrm{C} / \mathrm{HF}$.

Gene and protein expression studies. The expression of $\gamma H 2 A X$ mRNA was increased in the $\mathrm{HF} / \mathrm{HF}$ group compared with the $\mathrm{C} / \mathrm{C}$ group and $\mathrm{HF} / \mathrm{C}$ group (both $\mathrm{P}<0.05$; Fig. $3 \mathrm{~A}$ ). The expression of $F O X O 3 a$ mRNA in the ovaries of offspring in the $\mathrm{HF} / \mathrm{HF}, \mathrm{HF} / \mathrm{C}, \mathrm{C} / \mathrm{HF}$ and $\mathrm{C} / \mathrm{C}$ groups showed a decreasing trend (vs. $\mathrm{C} / \mathrm{C}$ group, all $\mathrm{P}<0.05$ ) (Fig. 3B). Higher expression of $I G F-1$ and Bim mRNAs was detected in the HF/HF group compared with the $\mathrm{HF} / \mathrm{C}$ group, and higher expression was observed in the $\mathrm{HF} / \mathrm{C}$ compared with the $\mathrm{C} / \mathrm{HF}$ group (both $\mathrm{P}<0.05$; Fig. 3C-D). In addition, the expression of each protein was analyzed using western blot analysis. The results of the western blot analyses were consistent with those of the RTq-PCR analysis (Fig. 4). Significantly higher BIM and FOXO levels were measured in the $\mathrm{HF} / \mathrm{HF}$ group compared with those in the $\mathrm{HF} / \mathrm{C}, \mathrm{C} / \mathrm{HF}$ and $\mathrm{C} / \mathrm{C}$ groups (all $\mathrm{P}<0.05$ ).

\section{Discussion}

The Developmental Origins of Health and Disease concept has emerged over the past 50 years, describing how maternal and environmental factors potentially affect the child's growth and development (10). The environment of the maternal uterus not only affects the growth of embryos but also exerts a long-term effect on the health of the offspring, a phenomenon known as fetal programming (11). An mice model study revealed that maternal HFD decreases the number of follicles in the ovaries of offspring $(12,13)$. In the present study, the offspring mice of a mother fed an HFD had fewer follicles compared with the mice

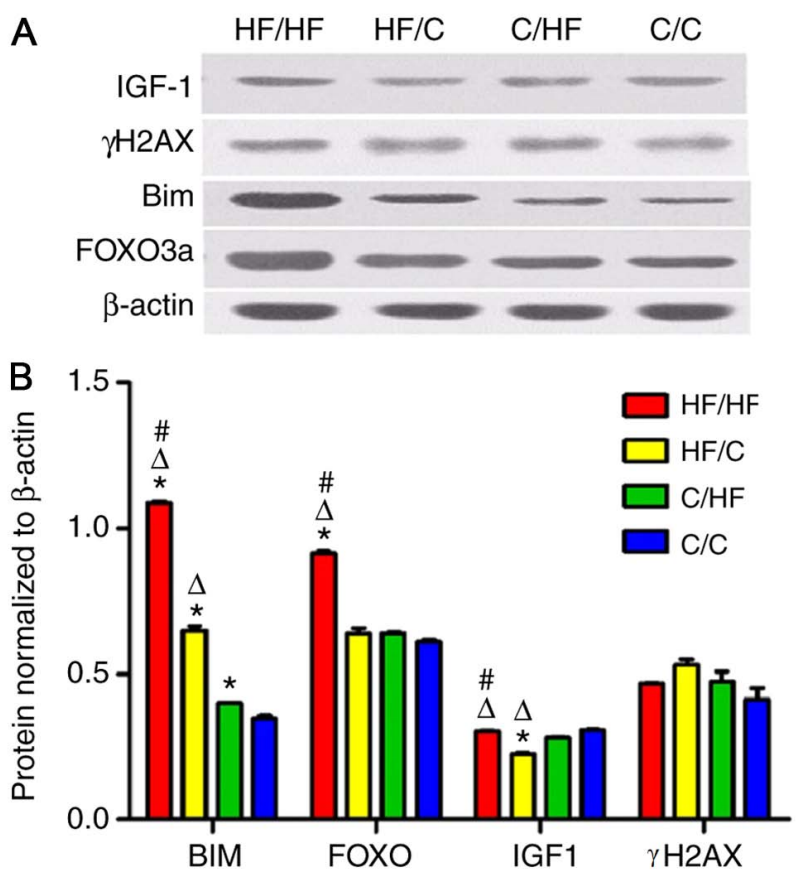

Figure 4. The $\gamma \mathrm{H} 2 \mathrm{AX}$, FOXO3a, Bim and IGF-1 protein expression level. (A) Western blot analyses were performed to determine protein levels. (B) The level of protein was normalized to $\beta$-actin levels. All values are reported as mean \pm SEM. ${ }^{*} \mathrm{P}<0.01$ vs. the $\mathrm{C} / \mathrm{C}$ group; ${ }^{\#} \mathrm{P}<0.01$ vs. the $\mathrm{HF} / \mathrm{C}$ group; ${ }^{\Delta} \mathrm{P}<0.01$ vs. the $\mathrm{C} / \mathrm{HF}$ group (one-way ANOVA). FOXO3a, forkhead box protein O3a; IGF-1, insulin-like growth factor 1; $\gamma \mathrm{H} 2 \mathrm{AX}$, phosphorylated form of $\mathrm{H} 2 \mathrm{AX}$ histone variant; Bim, Bcl-2-like protein 11; HF, high fat; $\mathrm{C}$, control.

born to a mother who was fed a regular diet. Moreover, exposure to an HFD during pregnancy affected the reproductive function of offspring, based on results obtained from the $\mathrm{C} / \mathrm{HF}$ and $\mathrm{C} / \mathrm{C}$ groups. A reduction in fat intake significantly reduced the associated adverse outcomes, as demonstrated by the difference 
in results obtained from the $\mathrm{HF} / \mathrm{HF}$ and $\mathrm{HF} / \mathrm{C}$ groups. Exposure to an HFD during the preconception period exerted a greater effect on the offspring compared with exposure to an HFD in the gestational and lactation periods, as shown in the $\mathrm{HF} / \mathrm{C}$ and $\mathrm{C} / \mathrm{HF}$ groups. Thus, an HFD during the preconception period resulted in much greater impact on follicular growth and development in the ovaries of offspring. It is speculated that these changes might be caused by several factors, such as changes in oocyte quality, maternal obesity and metabolic changes, which require further study. Since obesity may lead to lower fertility in women through alterations in various metabolic pathways, including insulin metabolism, sex hormones and follicular development (13), the current study detected serum levels of insulin, testosterone and FSH in mothers and their female mice offspring. Both the dams and offspring in the HF/HF group presented an increased levels of insulin and a tendency towards insulin resistance. A reduction in fat intake during the pregnancy and lactation periods effectively improved the insulin levels and insulin resistance, as the insulin level showed a decreasing trend: $\mathrm{HF} / \mathrm{HF}>\mathrm{HF} / \mathrm{C}>\mathrm{C} / \mathrm{HF}>\mathrm{C} / \mathrm{C}$. Insulin resistance has been shown to stimulate the ovaries to secrete excessive androgens, causing FSH-grain cell axis dysfunction (14). Consistent with the present study, the analysis of mouse serum samples showed that HFD-exposed offspring had increased levels of testosterone and decreased levels of FSH.

The current study detected OS markers (SOD and MDA) and analyzed the expression of OS-related genes in the ovaries of adult offspring mice to further explore the underlying pathogenic mechanisms of an HFD. OS was substantially higher in the HFD group $\mathrm{HF} / \mathrm{HF}, \mathrm{HF} / \mathrm{C}, \mathrm{C} / \mathrm{HF}$ ) compared with in the control group, as demonstrated by lower SOD and higher MDA levels. SOD levels showed an increasing trend among the $\mathrm{HF} / \mathrm{C}, \mathrm{C} / \mathrm{HF}$ and $\mathrm{C} / \mathrm{C}$ groups $(\mathrm{P}<0.05)$, while MDA levels showed the opposite trend. A higher level of OS was observed in the offspring of the HFD groups compared with the offspring of the control group, suggesting that even after removing pathogenic factors, the negative effect on the offspring persisted. Fortunately, OS was significantly improved by reducing fat intake, as shown by the increase in SOD levels $(\mathrm{HF} / \mathrm{HF}<\mathrm{HF} / \mathrm{C}<\mathrm{C} / \mathrm{HF}<\mathrm{C} / \mathrm{C})$ and the decrease in MDA levels $(\mathrm{HF} / \mathrm{HF}>\mathrm{HF} / \mathrm{C}>\mathrm{C} / \mathrm{HF}>\mathrm{C} / \mathrm{C})$ among groups. Usually, OS occurs when the body produces excess ROS, causing imbalances with antioxidants. The consumption of an HFD usually results in a large number of fatty acids. The consumption of SOD during fatty acid oxidation causes the accumulation of the peroxide free radical MDA $(6,15)$. With the increased production of free radicals, an OS response is more likely to occur (7). One of the limitations of the present study was that there was no analysis the levels of superoxide anions and hydrogen peroxide. The increased OS level may be caused by DNA damage, while OS further increased DNA damage, causing a vicious cycle (16).

Regarding the gene expression analysis, $H 2 A X$, a member of the histone H2A family, is necessary for OS-induced DNA damage. When damage occurs, $\mathrm{H} 2 \mathrm{AX}$ is quickly phosphorylated at Ser139 to produce $\gamma \mathrm{H} 2 \mathrm{AX}$, creating a marker of DNA damage (17). In the present study, $\gamma \mathrm{H} 2 \mathrm{AX}$ expression increased in offspring of the HFD groups. Based on these findings, cellular DNA in the offspring of mothers fed an HFD is more vulnerable to damage $(16,18)$. FOXO3a has critical functions in the repair of damaged cellular DNA and participates in the regulation of primordial follicle formation, follicle development and oocyte apoptosis (19). The present study revealed increased expression of FOXO3a in the ovaries of offspring from the HFD groups. FOXO expression is modulated by the insulin/PI3K/Akt pathway, the main pathway involved in insulin signal transduction. In the absence of insulin, FOXO is located in the nucleus and functions as a transcription factor by binding to the target gene promoter. When insulin activates the PI3K/Akt pathway, FOXO is phosphorylated. Phosphorylated FOXO does not bind the target gene promoter and is transferred from the nucleus to the cytoplasm, losing its transcriptional function. When insulin resistance is present, the sensitivity of insulin is reduced $(19,20)$. As the signal transmission of the $\mathrm{PI} 3 \mathrm{~K} / \mathrm{Akt}$ pathway is weakened, FOXO transcription increases, thereby affecting glucose metabolism, resulting insulin resistance (19-21). Consistent with these findings, both the HFD groups and corresponding offspring exhibited increased levels of insulin and a tendency towards insulin resistance in the current study. In addition, the DNA damage and subsequent OS also induced the expression of FOXO3a to repair the damaged cells. Thus, it was speculated that the increase in FOXO3a expression in offspring was modulated by the insulin/PI3K/Akt pathway. This change may be associated with insulin resistance and increased levels of OS caused by the HFD. Further studies are needed to validate this conclusion.

In summary, an HFD during the preconception period resulted in long-term consequences on follicular growth and development in the ovaries of adult offspring mice. HFD exposure during the preconception period exerted a greater effect on offspring compared with HFD exposure during the gestational and lactation periods. A reduction in HF intake during the preconception, gestation and lactation periods improved the reproductive ability of female offspring. The present study revealed the adverse effects of the HFD on the reproductive function of offspring. It was speculated that DNA was more vulnerable to damage in mice fed the HFD, causing OS and insulin resistance. OS, DNA damage and insulin resistance may have increased the expression of $\mathrm{FOXO} 3 \mathrm{a}$, which protects cells from OS-induced damage (22); however, this adaptation to an adverse intrauterine environment affected the number of the ovaries. The long-term effects on follicular growth and development might be involved in increasing OS and the activation of the insulin/PI3K/Akt pathway. Further studies are needed to confirm these conclusion.

\section{Acknowledgements}

Not applicable.

\section{Funding}

This study was funded by the National Natural Science Foundation of China (grant no. 81471521).

\section{Availability of data and materials}

The datasets used and/or analyzed in the current study are available from the corresponding author on reasonable request. 


\section{Authors' contributions}

All authors contributed to the study conception and design. QS was responsible for the integrity of the work as a whole from inception to the published article, such as performing animal experiments and writing the manuscript. SY and FW collected the data and performed the statistical analysis. All authors read and approved the final manuscript.

\section{Ethics approval and consent to participate}

Ethics committee approval was obtained from the Institutional Ethics Committee of Capital Medical University (Beijing, China). All animals were provided by the Laboratory Animal Center of Capital Medical University, and the study protocol was approved by the Capital Medical University Ethics Review Committee (Capital Medical University Beijing Obstetrics and Gynecology Hospital; approval no. AEEI-2019-111).

\section{Patient consent for publication}

Not applicable.

\section{Competing interests}

The authors declare that they have no competing interests.

\section{References}

1. McIntyre HD, Catalano P, Zhang C, Desoye G, Mathiesen ER and Damm P: Gestational diabetes mellitus. Nat Rev Dis Primers 5: 47, 2019.

2. Poston L, Caleyachetty R, Cnattingius S, Corvalán C, Uauy R, Herring $\mathrm{S}$ and Gillman MW: Preconceptional and maternal obesity: Epidemiology and health consequences. Lancet Diabetes Endocrinol 4: 1025-1036, 2016.

3. Stephenson J, Heslehurst N, Hall J, Schoenaker DA, Hutchinson J, Cade JE, Poston L, Barrett G, Crozier SR, Barker M, et al: Before the beginning: Nutrition and lifestyle in the preconception period and its importance for future health. Lancet 391: 1830-1841, 2018

4. Hohos NM and Skaznik-Wikiel ME: High-fat diet and female fertility. Endocrinology 158: 2407-2419, 2017.

5. Cheong Y, Sadek KH, Bruce KD, Macklon N and Cagampang FR: Diet-induced maternal obesity alters ovarian morphology and gene expression in the adult mouse offspring. Fertil Steril 102: 899-907, 2014
6. Lu J, Wang Z, Cao J, Chen Y and Dong Y: A novel and compact review on the role of oxidative stress in female reproduction. Reprod Biol Endocrinol 16: 80, 2018.

7. Di Segni C, Silvestrini A, Fato R, Bergamini C, Guidi F, Raimondo S, Meucci E, Romualdi D, Apa R, Lanzone A and Mancini A: Plasmatic and intracellular markers of oxidative stress in normal weight and obese patients with polycystic ovary syndrome. Exp Clin Endocrinol Diabetes 125: 506-513, 2017.

8. Catalano PM and Shankar K: Obesity and pregnancy: Mechanisms of short term and long term adverse consequences for mother and child. BMJ 356: j1, 2017.

9. Livak KJ and Schmittgen TD: Analysis of relative gene expression data using real-time quantitative PCR and the 2(-Delta Delta C(T)) method. Methods 25: 402-408, 2001.

10. Mochizuki K, Hariya N, Honma K and Goda T: Relationship between epigenetic regulation, dietary habits, and the developmental origins of health and disease theory. Congenit Anom (Kyoto) 57: 184-190, 2017.

11. Hanson M, Barker M, Dodd JM, Kumanyika S, Norris S, Steegers E, Stephenson J, Thangaratinam S and Yang H: Interventions to prevent maternal obesity before conception, during pregnancy, and post partum. Lancet Diabetes Endocrinol 5: 65-76, 2017.

12. Da Broi MG, Giorgi VSI, Wang F, Keefe DL, Albertini D and Navarro PA: Influence of follicular fluid and cumulus cells on oocyte quality: Clinical implications. J Assist Reprod Genet 35: 735-751, 2018.

13. Hohos NM, Cho KJ, Swindle DC and Skaznik-Wikiel ME: High-fat diet exposure, regardless of induction of obesity, is associated with altered expression of genes critical to normal ovulatory function. Mol Cell Endocrinol 470: 199-207, 2018.

14. Petrakis D, Vassilopoulou L, Mamoulakis C, Psycharakis C, Anifantaki A, Sifakis S, Docea AO, Tsiaoussis J, Makrigiannakis A and Tsatsakis AM: Endocrine disruptors leading to obesity and related diseases. Int J Environ Res Public Health 14: 1282, 2017.

15. Radin L, Šimpraga M, Vince S, Kostelić A and Milinković-Tur S: Metabolic and oxidative status of Saanen goats of different parity during the peripartum period. J Dairy Res 82: 426-433, 2015.

16. Bisht S, Faiq M, Tolahunase M and Dada R: Oxidative stress and male infertility. Nat Rev Urol 14: 470-485, 2017.

17. Turinetto V and Giachino C: Multiple facets of histone variant H2AX: A DNA double-strand-break marker with several biological functions. Nucleic Acids Res 43: 2489-2498, 2015.

18. Gao T, Diaz-Hirashi Z and Verdeguer F: Metabolic signaling into chromatin modifications in the regulation of gene expression. Int J Mol Sci 19: 4108, 2018.

19. Lee S and Dong HH: FoxO integration of insulin signaling with glucose and lipid metabolism. J Endocrinol 233: R67-R79, 2017.

20. Ma J, Matkar S, He X and Hua X: FOXO family in regulating cancer and metabolism. Semin Cancer Biol 50: 32-41, 2018.

21. Manning BD and Toker A: AKT/PKB signaling: Navigating the network. Cell 169: 381-405, 2017.

22. Fasano C, Disciglio V, Bertora S, Lepore Signorile M and Simone C: FOXO3a from the nucleus to the mitochondria: A round trip in cellular stress response. Cells-Basel 8: 1110, 2019. 